U.S. DEPARTMENT OF HEALTH. EDUCATION, AND WELFARE CENTER FOR DISEASE CONTROL

NATIONAL INSTITUTE FOR OCCUPATIONAL SAFETY AND HEALTH CINCINNATI, OHIO 45202

HEALTH HAZARD EVALUATION DETERMINATION

REPORT NO. $76-18-288$

SYNTEX FABRICS, InC. WILLIAMSPORT, PENNSYLVANIA

MAY 1976

I. TOXICITY DETERMINATION.

It has been determined upon the basis of a combined environmental-medical evaluation conducted February 9-10, 1976 at Syntex Fabrics, Inc., Williamsport, Pennsylvania that a potential health hazard from exposure to dust containing cotton may exist to workers exposed in Area One of the Weaving Department. This determination is based upon environmental measurements of total dust and respirable dust containing cotton in Area One of the Weaving Department, medical histories and physical examinations of affected workers, and information contained in the NIOSH Criteria Document for Occupational Exposure to Cotton Dust. It is apparent, by the lack of positive findings characteristic of the disease, that no current problem of byssinosis exists at Syntex Fabrics, Inc. However, since the weaving process in question had only been in operation for eight weeks, the lack of findings would not exclude the future development of byssinosis. There is also evidence that upper respiratory irritation is present to a greater degree in workers from Area One than in the surrounding areas.

II. OISTRIBUTION AND AVAILABILITY OF DETERMINATION REPORT

Copies of this Determination Report are available upon request from NIOSH, Division of Technical Services, Information Resources and Dissemination Section, 4676 Columbia Parkway, Cincinnati, Ohio 45226. Copies have been sent to:

a) Syntex rabrics, Inc., Williamsport, Pennsylvania

b) Authorized Representative of Employees

c) U. S. Department of Labor - Region III

d) NIOSH - Region III

For the purpose of informing the approximately 25 "affected employees", the employer shall promptly "post" for a period of 30 calendar days the Determination Report in a prominent place(s) near where exposed employees work.

III. INTRODUCTION

Section 20(a)(6) of the Occupational Safety and Health Act of 1970, 29 U.S.C. $669(\mathrm{a})(6)$, authorizes the Secretary of Health, Education, and Welfare, following a written request by an employer or authorized 
Page 2 - Health Hazard Evaluation Determination 76-18

representative of employees, to determine whether any substance normally found in the place of employment has potentially toxic effects in such concentrations as used or found.

Syntex Fabrics Inc. is a producer of unfinished, undyed cloth of many different types. On approximately November 22, 1975, a new combination of materials was put into production in Area One. This change consisted of weaving a 100\% Dacron Polyester with a 50\% Dacron Polyester, $50 \%$ Cotton blend. Four weeks after production began, workers in Area One and the immediate surrounding areas began to complain of sore and dry throat, eye irritation, cough and shortness of breath. The workers involved numbered approximate1y 20-25. Throughout the second four weeks of production these symptoms were reported with increasing frequency and a request for health hazard evaluation was submitted jointly by management and labor.

\section{HEALTH HAZARD EVALUATION}

\section{A. Plant Process - Conditions of Use}

The area of the request is part of the Weaving Department of a mi11 providing a variety of unfinished, undyed cloth. The looms in the Weaving Department are divided into four numbered areas. Area One is the only area in which yarn containing cotton is woven. This cloth is basically a 70-30 polyester/cotton "plain" weave used for outerwear. It is approximately $51^{11}$ in width and is in greige goods classification when it leaves this plant - i.e. unfinished and not dyed.

A "warp" is made in the Sizing Department and prepared in the Knotting Department for weaving. It is made up of $100 \%, 150 / 34 / R 02$, type 56 , semi-dul1 Dacron (Polyester). This warp is then taken to the Weaving Department and placed in a loom. At this point the cloth is made by the loom automatically inserting another type yarn into the warp at right angles. This yarn is called "filling" yarn and is made of $16 / 1$ spun $50 \%$ polyester $/ 50 \%$ cotton, AYP - 1611 . The finished cloth is then "taken-up" on a cloth roll and manually collected for shipment.

There are three workers assigned to the Area One who remain in the area during the entire shift: loom fixer, weaver, and smash fixer; consequently these workers would be expected to have the greatest potential exposure to dust containing cotton. The cut boy, equipment tender, utility man and janitor are assigned to Areas One - Four and are not required to be in the area during the entire shift and for this reason may have lower exposure to dust than the loom fixer, weaver, and smash fixer. There are workers in Areas Two and Four who may have some exposure due to infiltration of dust into their work areas.

The employees at Syntex Fabrics Inc. number 143 (21 administrative personnel, 120 production personnel and two maintenance personne1). The company has six female employees in the office, and only one female employee working in the weaving area. The rest of the total number of employees consist of white males. The workers are members of the Textile Workers of America Local \#186. 
Three shifts per day, five days per week, operate at syntex. The first 6:00 a.m. - 2:00 p.m., the second 2:00 p.m. - 10:00 p.m. and the third 10:00 p.m. - 6:00 a.m.

The average age of those workers involved in this health hazard evaluation was 35.7 years, with a range of 18 to 65 years. The average time at Syntex, Inc. for these workers was 9.1 years, with a range of three weeks to 23 years.

Syntex, Inc. provides first aid treatment on the factory grounds. Emergency coverage is provided at the emergency rooms of two local hospitals that are within 10-15 minutes traveling time. There are no full-time medical employees and no written contracts for provision of medical care. However, there is a verbal contract with a physician to conduct pre-employment examination, but does not require any annua? examination or termination examination. Chest $x$-rays are done on a yearly basis by the local American Tuberculosis Society and are strictly voluntary. There have been no industrial hygiene services or sampling done at Syntex, Inc., and the Committee for Employment Safety is comprised of volunteer workers, who serve on this Committee.

OSHA has visited Syntex, Inc. and the primary problem defined by them consists of elevated noise levels in the weave room. As the result all workers are required to wear protective ear plugs or other devices.

In reviewing the management records for 1975, there were several cases involving back strain and three cases involving skin and eye irritation including one foreign body in the eye. The lost work time as a result of these problems was minimal.

Eating facilities for employees are nonexistent. The workers eat and drink for the most part in the area in which they are working or in close proximity to it. Restroom and washing facilities are present, both male and female, in an adjacent area of the plant that is relatively easily accessible.

\section{B. Evaluation Design}

\section{Environmenta1}

Personal samples were obtained to determine exposure to total dust for workers assigned to Area 1 as well as those assigned to adjacent areas. Area samples were obtained in Area 1 to determine workroom levels of total dust; dust, a fraction of which is cotton; and organics. Area filter samples also were obtained for examination using optical microscopy techniques. A bulk sample of the $50 \%$ polyester $/ 50 \%$ cotton yarn and settled particles collected on looms were obtained for solvent extration and infra red analysis to determine if any substances were present which might be associated with irritation in exposed workers. 
Page 4 - Health Hazard Evaluation Determination 76-18

2. Medical

During the visit to Syntex Inc. a total of 29 workers were examined. This consisted of 10 workers from the first shift, nine workers from the second shift, and 10 workers from the third shift. The workers were evaluated by questionnaire, a copy of which is enclosed in this report, and by a physical examination consisting of evaluation of the eyes, nose, oral pharynx and examination of the lungs.

All employees in Area One were evaluated as well as those from adjacent areas and a small number who worked throughout the plant.

C. Evaluation Methods

1. Samples for total dust concentration

Personal and area samples for measurement of total dust concentrations were obtained using a polyvinyl chloride filter with a 5.0 u average pore size held in a field cassette with only the pin removed during sampling. Flow rate was controlled at 1.51 iters/minute during the sampling period and weight increase was determined gravimetrically.

2. Samples for microscopic examination

Area samples for examination by optical microscopy were obtained using a mixed esters of cellulose filter with a 0.8 u average pore size held in an open face field cassette using a flow rate of 2.0 liters/minute during the sampling period.

\section{Cotton dust sampling}

Samples for evaluation of air concentrations of dust containing cotton in the work area were obtained at two locations using the vertical elutriator of Lumsden-Lynch as recommended in the NIOSH Criteria Document. Flow rate was controlled at $7.4 \pm 0.2$ 1iters/minute with a limiting orifice and vacuum pump. Dust was collected on a polyvinyl chloride filter with an average pore size of $5.0 \mathrm{u}$ and weight increase determined gravimetrically.

4. Butk samples for solvent extraction and infra red analysis

Samples of settled Tint were obtained from several looms in Area One. These bulk samples and a sample of yarn were extracted with carbon tetrachloride by a Soxhlet extraction, and the extracted oil was then analyzed by infra red spectroscopy.

\section{Area samples for organic vapors}

Organic vapor samples were obtained with charcoal sampling tubes at a flowrate of $1.0 \mathrm{lpm}$, desorbed with carbon disulfide and analyzed by gas chromatography. 


\section{Evaluation Criteria}

The two major potential health hazards in this process are dusts containing cotton and dacron.

Cotton $^{1}$ - Certain components of cotton dust orimarily the bracts of the cotton plant have been implicated in the development of byssinosis. Byssinosis is characterized by the gradual onset of symptoms within hours of returning to work on Monday after a weekend absence from work. If exposure continues the initial Monday symptoms of tightness in the chest, dyspnea and cough recur throughout the week, but still remain more severe on the first work day. A severe irreversible ventilatory impairment may occur after exposure to the dust for at least 10 years and usually more than 20 years. The disease at this stage may be indistinguishable from chronic bronchitis and emphysema and is more likely to develop in those who experience characteristic Monday morning symptoms during the first year of employment. The principle sources of dust in the cotton textile manufacture are the fiber preparation and carding areas, followed by winding and spinning. Slashing and weaving (the process evaluated at Syntex) pose a much reduced potential hazard for the development of byssinosis.

The following is quoted from Chapter I of the NIOSH Criteria Document for Occupational Exposure to Cotton Dust. 2

"Since no definitive environmental level can assure complete health protection, none is recommended in this document. However, to ensure that effective engineering controls are implemented and dust concentrations reduced, an environmental standard should be fixed. The concentration should be set at the lowest level feasible in order to reduce the prevalence and severity of byssinosis. The criteria and standard will be subject to review and revision as necessary.

"Exposure to cotton dust" includes any work with cotton that results in airborne cotton dust; "cotton dust" is defined as dust generated into the atmosphere as a result of the processing of cotton fibers combined with any naturally occurring materials such as stems, leaves, bracts, and inorganic matter which may have accumulated on the cotton fibers during the growing or harvesting period. Any dust generated from processing of cotton through the weaving of fabric in textile mills and dust generated in other operations or manufacturing processes using new or waste cotton fibers or cotton fiber byproducts from textile mills is considered cotton dust. The recommended standard does not apply to dust generated from the handling or processing of woven materials." .

Therefore the area of this request (Weaving Department) is defined as an area where workers have "exposure to cotton dust."

Dacron - This is a widely used material in many goods from clothing to heart valves and blood vessel prosthesis. There have been no reported toxic effects when used in the weaving of cloth. 
Page 6 - Health Hazard Evaluation Determination 76-18

E. Evaluation Results and Discussion

1. Physical inspection of the worksite

The NIOSH investigators conducted a physical inspection of the work areas on February 9, 1976 while accompanied by renresentatives of the employer and employees.

The weaving room is divided into four major areas. Area Number One was the one primarily involved in this health hazard evaluation. Approximately eight weeks prior to the NIOSH evaluation, Syntex Fabrics Inc began to weave a new combination of fibers. These consist of $100 \%$ Dacron Polyester, woven with a 50\% Dacron Polyester, 50\%. Cotton blend. The Dacron Polyester material is the same one that has been used in weaving different cloth goods in this particular company for many years. The new component is the $50 \%$ Dacron Polyester, 50\% Cotton blend. This particular blend was described to us as being "top of the line", however, upon close examination a large number of smal1 brown particles were detected throughout the entire spool. The suppliers stated that this material consisted of very fine wood fragments, but it had an appearance which could be cotton bract.

The alleged hazard involved in this process seemingly occurs as the blend yarn is wound on to the delivery apparatus. There was a considerable amount of "fly" that was quite visible to the naked eye. This fly could be seen to be accumulating in large amounts on the looms themselves, on the overhead humidification system and in other areas in the section that this weaving process was being performed. Other areas of the plant produce dust, but in much less visible quantities than in Area One.

\section{Environmental evaluation results and discussion}

The assessment of the potential health hazard associated with exposure to cotton dust is complicated by several factors. The identity of the substance(s) associated with byssinosis and other respiratory ailments of cotton workers has not been established. Some investigators have been able to establish correlations between dust exposure to workers and prevalance of byssinosis while others have not. Several sampling methods have been utilized by investigators, such as total dust, fly free cotton dust (excluding particles caught by a $2 \mathrm{~mm}$ mesh), and several respirable dust measurements. The preferred method of health hazard evaluation is that recommended by the NIOSH Criteria Document: measurement of cotton dust (< $15 \mathrm{um}$ ) using the Lumsden-Lynch vertical elutriator.

Table 1 contains the results of area sampling which was conducted during this evaluation to assess total dust and respirable dust containing cotton at two locations in Area 1 of the weaving room where the $50 \%$ polyester $/ 50 \%$ cotton yarn was being woven. All sample results were corrected by subtracting the average weight gain of eight blank filters which was $0.01 \mathrm{mg} / \mathrm{filter}$. The area measurements of respirable dust containing cotton are quite consistent in this evaluation ranging from 0.50 to $0.59 \mathrm{mg} / \mathrm{M}^{3}$ during the two shifts. A total of four sets of side-by-side area samples were obtained for both respirable and total dust during the evaluation. The respirable and total dust concentrations show similar 
dust levels with the exception of the first set collected adjacent to Looms 63 and 64 during the first shift. The total dust concentration for this set appears low in comparison to the other total dust results in Table 1 and may be due to an error in the sampling and/or analytical determination for this sample. The close agreement between respirable and total dust levels for the remaining three sets of samoles suggests that the dust is predominantiy in the respirable range (<15 um) collectad by the vertical elutriator. In two of these three sets of samples, slightly higher respirable than total dust loadings were observed, however, these differences are likely within the expected accuracy and associated variation for the sampling and analytical methods used. Two filter samples were also obtained at the two area locations during the first shift for microscopic examination. The majority of the particulate collected on both of these filters was observed to be less than 10 um by the analyst. No qualitative statement could be made regarding the presence or absence of particles of stems, leaves or bracts since the particle size was too small for identification by the optical microscopy techniques used. However, the results of respirable and total dust measurements and microscopic examination of collected dust, all indicate that the air concentrations of dust in Area 1 of the weaving room are predominantly in the respirable range ( $<15 \mathrm{ug}$ ). Merchant, et. a1. ${ }^{4}$ reported $5 \%$ byssinosis (a11 grades) at a concentration of $0.5 \mathrm{mg} / \mathrm{M}^{3}$ of $<15$ um dust in the slashing and weaving areas of American Mills. This dust level compares closely to the <15 um dust level measured in this study.

Table 2 contains the results of personal sampling for total dust conducted during this study; total dust for Area 1 workers ranged from 0.34 to 0.48 $\mathrm{mg} / \mathrm{M}^{3}$ with an average exposure of $0.42 \mathrm{mg} / \mathrm{M}^{3}$. Workers from Areas 1 through 4 and Areas 2 and 4 had exposures which in general were somewhat higher than Area 1 workers.

It should be noted that the sampling and analytical methods used in this evaluation are non-specific, defining dust levels for respirable or total particulate but do not identify the amount of active substance(s) originating from the cotton yarn which may be present in the dust. There are also other potential sources of dust in the weaving room: dust generated from the polyester yarn which comprises approximately $70 \%$ of the yarn woven in Area 1, dust generated from looms in Areas 2-4 of the weaving room, and ambient air pollution. The finish applied to the warp yarns may "slough off" during weaving and contribute to the dust loading in the weaving room. For these reasons, the work of Merchant, et. al. ${ }^{4}$ may not be directly applicable to the environmental conditions existing at Syntex Fabrics at the time of the field evaluation.

Two samples of settled lint and a sample of the cotton-polyester yarn were extracted with carbon tetrachloride in the Soxhlet extractor for 14 hours. A small amount of yellow-brown, oily residue remained from each sample after removal of the solvent. Infrared spectroscopic analysis of the residue did not indicate the presence of any specific organic functional groups. Interpretation of spectral results indicates that the material was probably a long chain aliphatic hydrocarbon. 
The two charcoal tube area samples obtained during the first shift on February 10, 1976 at the same locations as the total dust and vertical elutriator area samples were analyzed by gas chromatography-mass spectrometer techniques to identify compounds collected on the charcoal tubes. Traces of toluene and xylene were identified but at very low concentrations, less than $0.04 \mathrm{pom}$ for each of these compounds. There were also a series of compounds appearing to be aliphatic type hydrocarbons of very low concentrations, less than $0.08 \mathrm{ppm}$ for any of the hydrocarbons.

Possible sources of these trace substances were investigated using the gas chromatography-mass spectrometer instrument including: a charcoaf tube sample taken over a bulk sample of sizing solution, solutions of the oil extracted from the lint, and a sample of the carbon tetrachloride used to extract the lint. Gas chromatographic analysis of these three samples were negative, not revealing any of the peaks observed on the two charcoal tubes obtained in the weaving room. It is concluded that neither the sizing solution nor the yarn emit any identifiable organic vapors into the workroom air which might be associated with symptoms of eye or upper respiratory irritation and that concentrations of toluene, xylene, and aliphatic hydrocarbons measured by the charcoal tube sampling method were well below levels of industrial hygiene significance.

\section{Medical evaluation results and discussion}

A total of 29 workers at the Syntex, Inc., Williamsport, Pennsylvania were examined. The positive findings, both those elicited by the questionnaires and those discovered by physical examination are listed in the Tables enclosed ( 3 and 4 ).

Head congestion (51.7\%), coughing (48.2\%) and throat irritation (27.6\%) were the most common symptoms elicited; followed by shortness of breath $(24.1 \%)$, rhinorrhea $(17.2 \%)$, eye irritation $(14.0 \%)$, and chest pain $(6.8 \%)$. Physical examination revealed nasal mucous membrane erythema $(62.7 \%)$, oral pharynx mucous membrane erythema $(58.6 \%)$ and conjunctival injection (27.6\%) to be the most common findings followed by rales and ronchi in the lungs $(20.6 \%)$ that were heard at times with great difficulty because of close proximity of the examining areas to the weave room.

After analysis of the data it is apparent that there is a considerably higher percentage of positive responses from Area Number One with respect to upper respiratory symptomatology. The physical findings, as is not uncommonly found in cases of minor irritancy, are inconclusive.

In addition to the above findings, data on the smoking habits of those examined was also collected. Seventy-two percent $(72 \%)$ of those interviewed smoked tobacco. The distribution by areas of work is shown in Table 5 and did not vary significantly from area to area. 
Page 9 - Health Hazard Evaluation Determination 76-18

CONCLUSIONS:

It is apparent, by the lack of positive findings characteristic of the disease, that no current problem of byssinosis exists at Syntex, Inc. However, since the weaving process in question had only been in operation for eight weeks, the lack of findings would not exclude the future development of byssinosis. There is evidence that uoper respiratory irritation is present to a greater degree in Area One than in the surrounding areas. The workers who presented with signs and symptoms of cough, shortness of breath and positive lung examinations consistent with chronic bronchitis or emphysema were the heaviest smokers and their problems are probably related to smoking.

The environmental measurements indicate that a potential i arard to the health of employees may exist from exposure to dust containing cotton in Area 1 of the weaving room. Although the risk involved is difficult to estimate, the most appropriate comparison to be made is to the work of Merchant, et. a1. 4 where a $5 \%$ prevalence of byssinosis was reported for the slashing and weaving areas of American Mills at a dust concentration of $0.5 \mathrm{mg} / \mathrm{M}^{3}$ of 15 um dust which compares closely to the level of respirable dust measured at Syntex Fabrics, Inc. in this study. However, there are other potential sources of dust in the weaving room which could serve to dilute the dust originating from cotton and therefore the estimate of byssinosis risk from the work of Merchant may not directly apply to this study. It is important to note (because of the high percentage of smokers at Syntex Fabrics, Inc. (72\%)) that the prevalence of byssinosis in smokers was approximately twice that for nonsmokers. in the mills studied by Merchant.

V. RECOMMENDATIONS

1. It is recommended that Section 1 through Section 7 inclusively, Chapter I of the NIOSH Criteria Document for Cotton Dust be adopted by Syntex Fabrics, Inc. in order to provide the greatest possible degree of health protection for workers exposed in Area One of the Weaving Department. A copy of this document has been provided to (1) Syntex Fabrics, Inc. and (2) the Authorized Representative of Employees.

2. It is aiso recommended that audiometric testing be done as a part of the pre-employment examination and annually thereafter, and the preemployment chest $X$-ray be included as a part of the routine pre-work evaluation.

VI. REFERENCES

1. Occupational Medicine, Zenz, et.at., 1975.

2. Criteria for a recommended standard.... Occupational Exposure to Cotton Dust, HEW Publication No. (NIOSH) 75-118, 1974.

3. Byssinosis in Cotton Textile Workers, Boultuys, et.al. Annals Internal Medicine, Vol. 71, 2, 1969.

4. Merchant, J.A., Lumsden, J.C., Kilburn, K.H., O'Fallon, W.M., Ujda, J.R., Germin, V.H., Hamilton, J.D.: Dose response studies in cotton textile workers. J. Occup. Med. 15:222-30, 1973. 
Page 10 - Health Hazard Evaluation Determination 76-18

VII. AUTHORSHIP AND ACKNOWLEDGMENT

$\begin{array}{ll}\text { Report Prepared By: } & \begin{array}{l}\text { Robert E. Rosensteel, Chief } \\ \text { Industrial Hygiene Section } \\ \text { Channing R. Meyer, Chief } \\ \text { Medical Section }\end{array} \\ \text { Originating Office: } \quad & \begin{array}{l}\text { Jerome P. Flesch, Acting Chief } \\ \text { Hazard Evaluation and Technical Assistance Branch } \\ \text { Cincinnati, Ohio }\end{array}\end{array}$

Acknowledgments.

Medical Evaluation: Loren L. Hatch, 0.0.

Medical Officer

Environmental Evaluation: Jack O. Geissert

Industrial Hygienist

Laboratory Analyses: Barry R. Belinky

Chemist

Ardith A. Grote

Chemist 




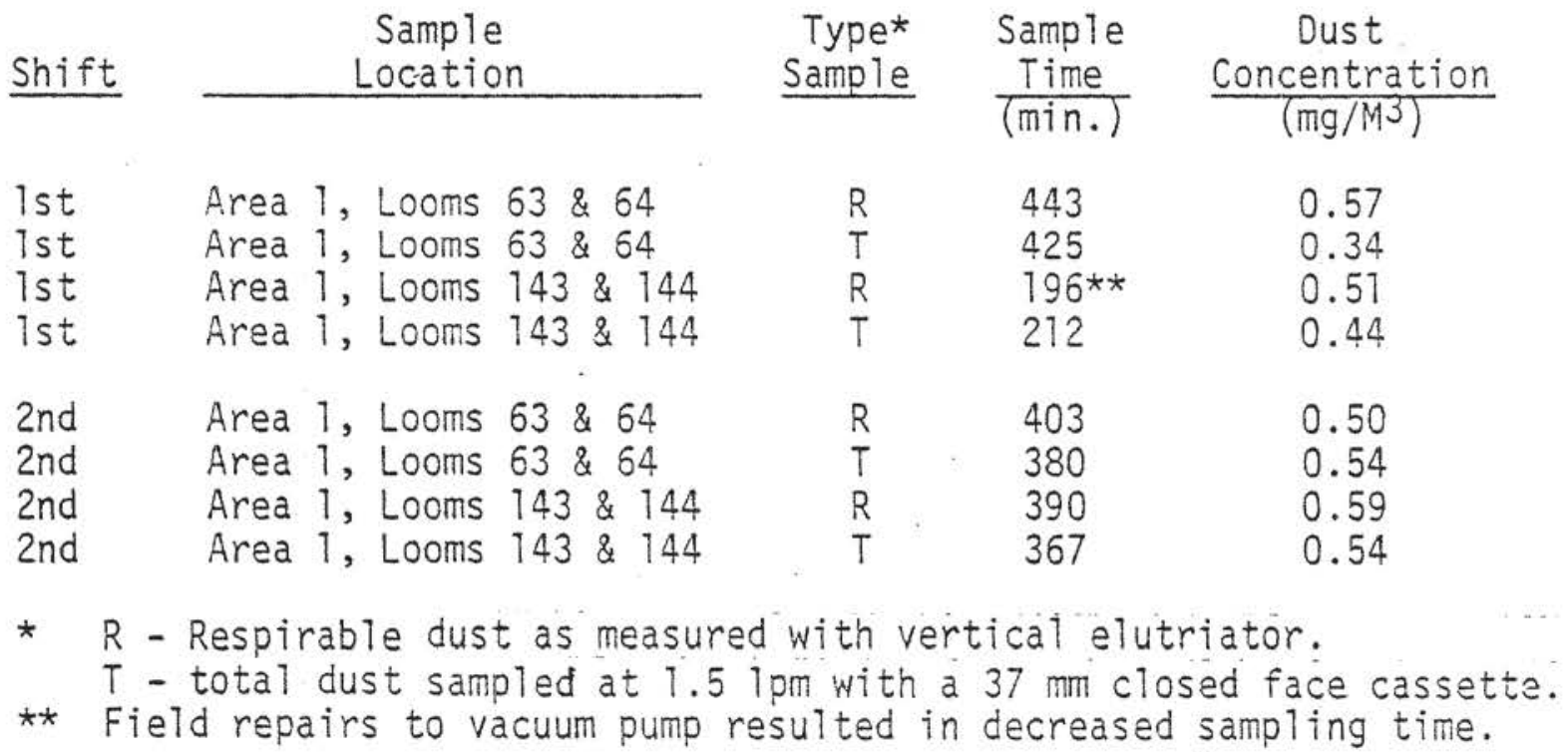


Table 2

Results of Personal Sampling for Exposure to Total Dust

(1st Shift)

Syntex Fabrics, Inc.

Williamsport, Pennsylvania

February 10, 1976

Tota.1 Dust

Job Description

Loom Fixer

Smash Fixer

Weaver

Laborer

Equipment Tender

Utility Man

Maintenance Worker

Loom Fixer

Smash Fixer

Loom Fixer

Smash Fixer
Work Area

Area 1

Area 1

Area 1

Area 1

Areas 1 thru 4

Areas 1 thru 4

Areas 1 thru 4

Area 2

Area 2

Area 4

Area 4 $\frac{\text { Sample Time }}{(\min .)}$

441
430
445
424
360
403
394
392
387
$315^{\star}$
409

Concentration

(mg/M3)

* Sampling device was removed in order to work in confined space. 
TABLE 3

SYMPTOMS BY HISTORY BY WORK AREAS

AT SYNTEX FABRICS, INC.

WILLIAMSPORT, PENNSYLVANIA

\% RESPONDERS BY

PERCENT WORK AREA

RESPONDING

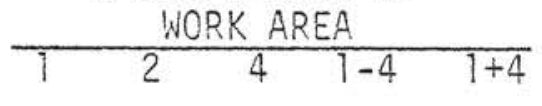

$\%$ SMOKERS

OF RESPONDERS

\begin{tabular}{lrrrrrrr}
\hline \multicolumn{1}{l}{ Total Workers } & & 13 & 6 & 6 & 2 & 2 & \\
Dry or Sore Throat & $27.6 \%$ & 43 & 17 & 17 & 0 & 0 & $87.5 \%$ \\
Eye Irritation & $14.0 \%$ & 31 & 0 & 0 & 0 & 0 & $75.0 \%$ \\
Head Congestion & $57.7 \%$ & 64 & 33 & 50 & 50 & 0 & $73.3 \%$ \\
Rhinorrhea & $17.2 \%$ & 8 & 17 & 33 & 50 & 0 & $80.0 \%$ \\
Coughing & $48.2 \%$ & 38 & 50 & 50 & 50 & 100 & $92.8 \%$ \\
Chest Pain & $6.8 \%$ & 8 & 17 & 0 & 0 & 0 & $100.0 \%$ \\
Shortness of Breath & $24.1 \%$ & 38 & 33 & 0 & 0 & 0 & $100.0 \%$
\end{tabular}




\section{TABLE 4}

PHYSICAL FINDINGS BY WORK AREAS

AT SYNTEX FABRICS, INC.

WILLIAMSPORT, PENNSYLVANIA

February 10, 1976

$\%$ RESPONDERS BY

\section{PERCENT}

RESPONDING

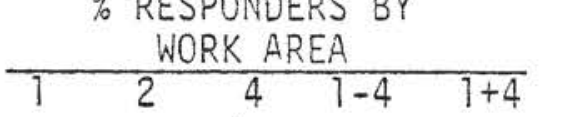

$\%$ SMOKERS OF RESPONDERS

Total Workers

Conjunctival Erythema

Nasal Mucous Membrane.

Erythema

Mouth \& Oral Pharynx

Mucous Membrane

Erythema

Lungs - Rales.

Lungs - Ronchi

$\begin{array}{lllll}13 & 6 & 6 & 2 & 2\end{array}$

$27.6 \%$

30

50

0

0

0

$100.0 \%$

$62.1 \%$

$\begin{array}{lllll}53 & 66 & 100 & 0 & 0\end{array}$

$83.3 \%$

$58.6 \%$

80.50

50

0

50

$94.1 \%$

$17.2 \%$

850

17

0

0

$100.0 \%$

$3.4 \%$

0

$\begin{array}{llll}17 & 0 & 0 & 0\end{array}$

$100.0 \%$ 


\section{TABLE 5}

PERCENTAGE SMOKERS BY WORK AREA

SYNTEX FABRICS, INC.

WILLIAMSPORT, PENNSYLVANIA

February 10, 1976

SMOKERS: $72 \%$ of those interviewed smoked tobacco

$\begin{array}{lcl}\text { AREA \#1 } & - & 69 \% \text { Smoked } \\ \text { AREA } \# 2 & - & 83 \% \text { Smoked } \\ \text { AREA } \# 4 & - & 83 \% \text { Smoked } \\ \text { AREA } \# 1-4 & - & 50 \% \text { Smoked } \\ \text { AREA } \# 1+4 & - & 50 \% \text { Smoked }\end{array}$


U.S. DEPARTMENT OF IFALTH, EDUCATION, AND WELFARE

PUBLIC HEALTH SERVICE

NATIONAL INSTITUTE FOR OCCUPATIONAL SAFEIY AND HEALTH

518 POST OFFICE BUILDING

CINCINNATI, OHIO 45202

\section{CONSENT}

I voluntarily agree to participate in a study at Syntex Company, Williamsport, Pennsylvania, conducted by the U.S. Public Health Service. I understand that the medical evaluation will consist of my answering questions about my health, a physical examination, if deemed necessary by the examining physician, and any other tests that may be required to carry out this evaluation.

I understand that my participation in this study is voluntary and that all information obtained will be considered confidential in accordance with U.S. Public. Health Service Regulation (42 CFR Part 1).

Date

Signature

AUTHORITY TO GIVE MEDICAL REPORT

I agree to allow the Public Health Service to inform:

A. My: personal physician

Name

Address

City

Signature

B. Plant Physician

Address

City

Signature

of any significant results of this study.

Information obtained in this study will be kept confidential in accordance with U.S. Public Health Service Regulation (42 CFR Part 1).

$(2 / 2 / 76)$ 
QUESTIONMAIRE

\#1

Study

U.S. DEPARTMENT OF HEALTH, EDUCATION, AND WELFARE

PUBLIC HEALTH SERVICE

NATIONAL INSTITUTE FOR OCCUPATIONAL SAFETY AND IIEALTH

CINCINNATI, OHIO 45202

1. Name

Last First Middle

2. Current Address: (Number, Street or Rural Route, City or Town, County, State, Zip Code)

3. Phone Number

4. Social Security No.

5. Birthday (Month, Day, Year)

6. Age Last Birthday

7. Sex: $\div$

Male

$2 \square$ Female

8. Race: Black

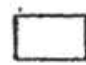

White

Other

How long at Syntex?

Shift Ist

2nd 
Complete the following table showing the entire work history of the individual from present to initial employment. Sporadic, part-time periods of employment ( 6 months or less) should be omitted.

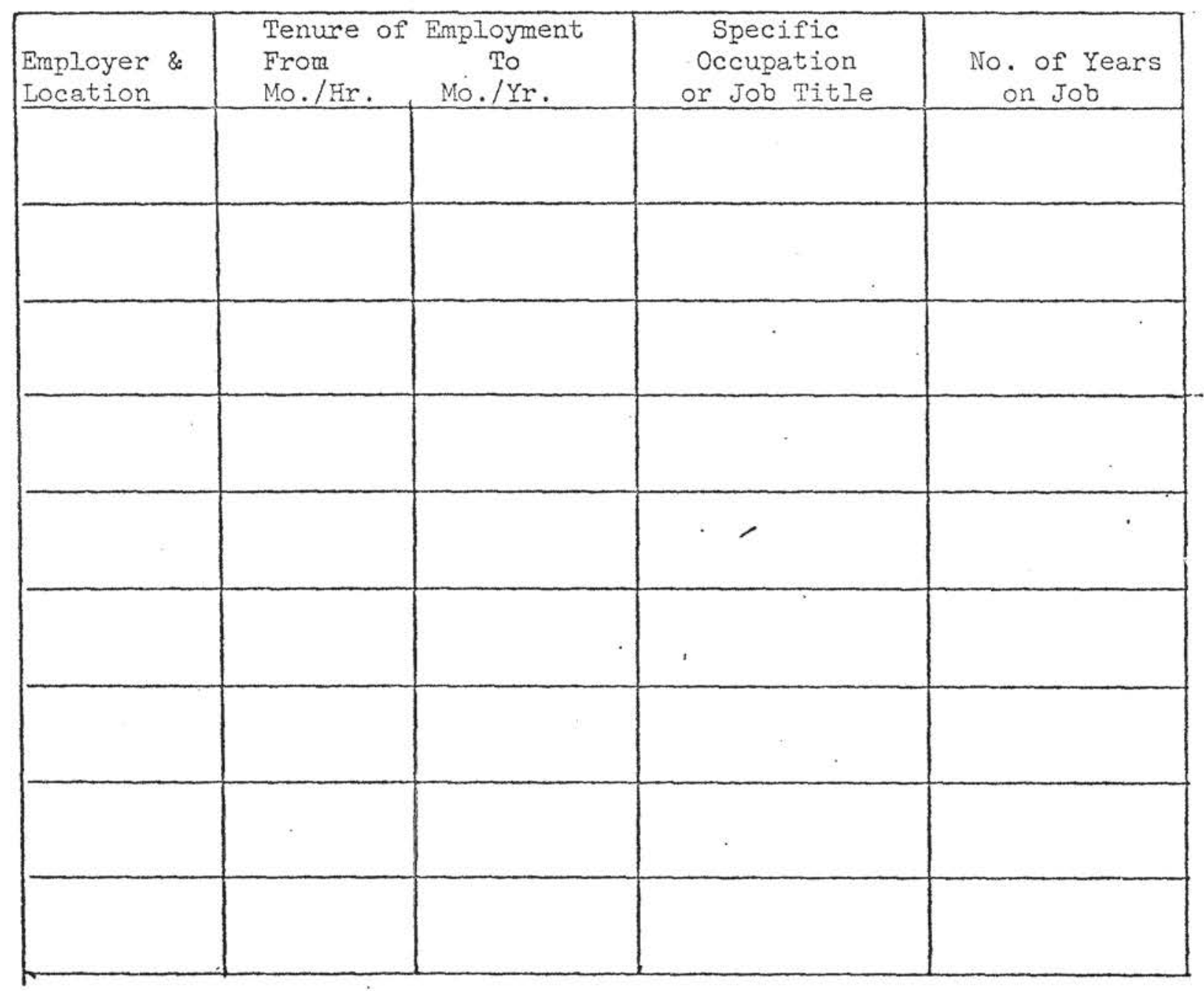


9. Do you have or have you had in the past any health complaints or problems which you feel may be related to your work at this plant?
Yes
No
If YES

a) What are they

b) What do you feel they are related to and why

c) When do they occur

d) Do they diminish after you leave work for the day or over the weekend when you are off work. . .

e) Have you seen a physician about the problem. Yes ___ No Details 
PAGE 4


authorize

(Personal and/or Company Physician)

\section{(Address)}

to release to the National Institute for Occupational Safety and Health (NIOSH) such of my medical records are requested by NIOSH as a part of Health Hazard Evaluation Number

Date

Signature of Worker

Witness 
PAGE 5

10. Do you have any other health complaints or problems which do not: seem related to your work? Yes No If "yes":

a. What? when? etc.

11. Have you ever had? ( $\vee$ or 0$)$

a. Chest or lung problems:

b. Heart problems

c. Pneumonia

d. Pulmonary $T B$

e. Bronchial asthma

f. Skin rash or other skin problems

g. Gastrointestinal problems

h. Kidney or bladder problems

i. Neurological problems

(Expound on any (+) findings):

12. Do you have any present problems for which you are seeing a doctor? Yes No If "yes", what are they?

13. Are you presently taking any medication? Yẹ No If yes, what medication?

14. Do you have or have you had any allergies in the past? Yes No If yes, what are they? If present or past, did you have this before working in the plant? Yes No

15. Have you ever had to change jobs in this plant because of health reasons? Yes No If yes, why and when? 
16. Have you ever had any of the following problems?

\begin{tabular}{|c|c|c|c|c|c|c|}
\hline PROBLEMS REIATED TO YOUR WORK & No & SONETIMES & USUALLY & REIATED TO WHAT & TIME & DURATION \\
\hline 1. Dry or sore throat & & & & & & \\
\hline 2. Burning or itching eyes & & & & & & \\
\hline 3. Tearing of the eyes & & & & & & \\
\hline 4. Stuffy nose & & & & & & \\
\hline 5. Runny nose & & & . & & & \\
\hline 6. Coushing & & & & & & $\therefore$ \\
\hline 7. Chest tightness, soreness, or heaviness & & & & & & \\
\hline 8. Wheezing or whistling in your chest. & & & & & & . \\
\hline 9. Shortness of breath & & & & . & & $\therefore$ \\
\hline 0 . Burning on urination & & . & & & & \\
\hline 1. Nausea and/or vomiting & & & & & & \\
\hline 2. Weight loss & & & & & . & \\
\hline 3. Muscle weakness & & & & & & \\
\hline 4. Loss of consciousness & & & & . & & \\
\hline
\end{tabular}


PAGE 7

\section{SMOKING HISTORY}

17. Are you presently:
a. a cigarette smoker? Yes
No
How much
How long
b. a cigar smoker?
Yes
No
How much
How long
c. a pipe smoker?
Yes
No
How much
How long

18. Were you ever:
a. a cigarette smoker? Yes
No
How much
How long
b. a cigar smoker?
Yes
No
How much How long
c. a pipe smoker?
Yes
No How much How long 
PAGE 8

PHYSICAL EXAMINATION

DATE

Patient's Name

cefers?

Eyes

Conjunctiva

Tearing present

Nose

Mouth and Oral Pharynx

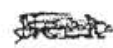

Lungs

Other

Positive Findings 